\title{
Faktor yang Berhubungan dengan Kejadian Carpal Tunnel Syndrome (CTS) pada Karyawan SPBE Di Indramayu
}

\author{
Factors Associated with the Occurrence of Carpal Tunnel Syndrome (CTS) in SPBE Employees in \\ Indramayu
}

\author{
Muthoharoh $^{1}$, Sarinah Basri K ${ }^{2}$, Tating Nuraeni ${ }^{3}$ \\ 1,2,3 Program Studi Kesehatan Masyarakat Universitas Wiralodra \\ e-mail : b_sarinah@yahoo.com
}

\begin{abstract}
Abstrak
CTS merupakan gangguan umum yang berhubungan dengan pekerjaan, disebabkan oleh gerakan berulang dan posisi yang menetap pada jangka waktu lama. Beberapa faktor diketahui menjadi risiko terjadinya CTS, seperti gerakan berulang dengan kekuatan, tekanan pada otot, postur kerja yang tidak ergonomik dan lain-lain.

Penelitian ini menggunakan Cross Sectional dengan jumlah sampel 40 karyawan di dua SPBE bagian Filling Hall area. Fisher Exact Test digunakan untuk analisis data uji statistik. Variabel yang diteliti adalah masa kerja, gerakan repetitive dan postur kerja. Dalam pengumpulan data peneliti menggunakan kuesioner, lembar observasi RULA dan test pemeriksaan fisik.

Hasil uji statistik menggunakan Fisher Exact Test untuk masa kerja dan postur kerja didapatkan nilai $P$-Value $=0,029$ dan 0,041. Karena nilai $P$-Value $<0,05$ sehingga Ho ditolak, artinya ada hubungan antara masa kerja dan postur kerja dengan kejadian CTS . sedangkan untuk gerakan repetitive hasil uji statistik menggunakan Fisher Exact Test didapatkan nilai $P$-Value $=0,464$. Karena nilai $P$-Value $>0,05$ sehingga $\mathrm{Ho}$ diterima, artinya ada hubungan antara gerakan repetitive dengan kejadian CTS.
\end{abstract}

Kata Kunci: Carpal Tunnel Syndrome, Masa Kerja, Gerakan Repetitive, Postur Kerja

\section{Abstract}

CTS is a common disorder that is associated with the work, caused by repetitive movements and positions are settled on a long term. Some of the factors known to be risks to the occurrence of CTS in workers, such as repetitive movements with vorse, the pressure on the muscles, work posture which not, ergonomic and other.

This study is Cross Sectional with a total sample of 40 employees in two SPBE part of the Filling Hall Area. Fisher Exact Test used for data analysis a statistical test. The variables studied are the factors of the period of employment, factor movements repetitive and posture work. In data collection the researches used questionnaire, observation, sheet RULLA and test a physical examination.

The results of statistical tests using Fisher Exact Test to the work obtained and posture work P-value $=0,029$ and
0,041 . Because the value of $P$ - value $<0,05$ so h0 is rejected, meaning that there relationship was enough between working period with the incidence of CTS.as for the movement of the repetitive test results statistics using the Fisher Exact Test obtained P-Value $=0,464$ because $P$-value $>0,05$ so $\mathrm{H} 0$ accepted, meaning that there is a relationship weak between the movement repetitive with the incidence of CTS.

Keywords: Carpal Tunnel Syndrome, The Labor, Movement Repetitive, Posture Work

\section{Pendahuluan}

Tenaga kerja merupakan sumber daya manusia yang mempunyai peranan penting sebagai pelaksana pembangunan, tanpa tenaga kerja yang produktif dan berkualitas maka pembangunan akan terlambat. Setiap jenis pekerjaan mempunyai resiko yang berbeda satu sama lain, diperlukan adanya perlindungan terhadap tenaga kerja dalam rangka peningkatan kesejahteraan secara menyeluruh $^{1}$.

OSHA (Occupational Safety and Health Administration) menyatakan bahwa faktor risiko yang berhubungan dengan pekerjaan yang menyebabkan Musculoskelatal Disorders adalah faktor pekerjaan itu sendiri seperti postur kerja, gerakan berulang, kecepatan kerja, kekuatan gerakan, getaran dan suhu, karakteristik lingkungan kerja, serta alat kerja yang digunakan ${ }^{2}$.

Salah satu jenis penyakit Musculoskelatal Disorders adalah CTS (Carpal Tunnel Syndrome). CTS merupakan gangguan pada anggota tubuh bagian tangan yang menyebabkan rasa sakit dan mati rasa terutama 
pada ibu jari dan tiga jari utama yaitu jari telunjuk, jari tengah, dan sebagian jari manis. CTS muncul ketika syaraf Medianus mengalami kompresi pada saluran dalam pergelangan tangan ${ }^{3}$.

CTS secara khas menyebabkan rasa nyeri dan parestesi pada tangan pada malam hari atau bengkak yang menyebabkan ketidakmampuan kondisi pergelangan tangan, karena tekanan yang terlalu berat pada syaraf medianus yang melalui pergelangan tangan (Carpal Tunnel) yang sempit, di bawah ligamentum karpal transversal ${ }^{4}$.

Gejala CTS meliputi rasa nyeri, pembengkakan, rasa seperti tertusuk, hipotesia pada ibu jari, telunjuk dan jari tengah. Penelitian Trimanto (2008) dalam Lazuardi (2016) menjelaskan bahwa dari 60 sampel terdapat 26 orang mengalami CTS dengan hasil ada hubungan antara masa kerja, frekuensi gerakan berulang, kekuatan otot tangan, sikap kerja dengan kejadian carpal tunnel syndrome pada pekerja pemecah batu split di desa Pandawa Kecamatan Lebaksiu Kabupaten Tegal. Dari posisi kerja yang bersifat monoton, menggunakan tangan secara fleksi dan ekstensi secara berlebihan, posisi kerja yang statis merupakan faktor resiko untuk terjadinya $\mathrm{CTS}^{5}$.

Di Indonesia, prevalens CTS dalam masalah kerja belum diketahui karena sangat sedikit diagnosis penyakit akibat kerja yang dilaporkan. Berbagai penelitian melaporkan bahwa CTS merupakan salah satu jenis CTDs yang paling cepat menimbulkan gejala pada pekerja. Penelitian pada pekerjaan dengan risiko tinggi di pergelangan tangan dan tangan mendapatkan prevalensi CTS antara 5,6\%$14,8 \% \%^{6}$. Penyebab dari CTS dapat terjadi karena trauma langsung pada carpal tunnel, posisi pergelangan fleksi dan ekstensi berulang, edema, kelainan sistemik ${ }^{7}$.

Salah satu pekerjaan yang banyak melakukan aktivitas statis dengan gerakan berulang adalah menjadi operator, loading bongkar dan loading muat gas elpiji. Dari proses pengisian gas (operator), loading bongkar dan loading muat diketahui faktor pekerjaan yang merupakan faktor risiko terjadinya CTS. Pada proses loading, saat mengangkut tabung gas dari Armada, pekerja menggunakan alat bantu berupa troli untuk mengangkut tabung, namun alat tersebut mengandalkan kekuatan tangan dengan cara didorong menuju conveyor. Posisi tangan dan tubuh bagian atas terlihat tidak ergonomik, posisi terlihat flexi dan extensi. Gerakan tangan tersebut dilakukan secara terusmenerus. Jika hal tersebut dilakukan secara berulang maka akan menyebabkan tekanan pada tangan atau pergelangan tangan.

Dari hasil studi pendahuluan yang dilaksanakan di SPBE PD.BWI pada bulan Februari 2017 ditemukan adanya gejala CTS pada karyawan seperti seringnya kesemutan dan rasa nyeri yang menjalar kejari serta tangan, salah satu faktor resiko yang menyebabkan sindrom terowongan karpal seperti gerakan berulang dengan kekuatan, tekanan pada otot, getaran, suhu, postur kerja yang tidak ergonomik. Mayoritas pekerja menganggap keluhan sakit atau nyeri pada tangan adalah hal yang biasa, sehingga sakit atau nyeri yang didapat tidak terlalu diperhatikan.

\section{Metode Penelitian}

Dalam melaksanakan penelitiaan, jenis penelitian yang digunakan adalah Observasional Analitik dengan menggunakan metode Cross Sectional, yaitu penelitian untuk mempelajari dinamika korelasi antara faktor resiko dengan efek, dengan cara pendekatan, observasi atau pengumpulan data sekaligus pada suatu saat atau Point Time Approach ${ }^{8}$.

Instrumen Penelitian adalah perangkat yang digunakan untuk mengungkap data ${ }^{9}$. Alat pengumpulan data yang digunakan dalam 
penelitian ini adalah Kuesioner, Phalen's test, Tinel test, Wrist extension test, Pressure test, Stopwatch, dan lembar penilaian RULA (Ruppid Upper Limb Assassment).

Dalam penelitian ini, peneliti akan membagikan kuesioner, observasi dan test pemeriksaan fisik pada karyawan karyawan bagian filling hall area di SPBE PD.BWI dan SPBE PT. Fajar Cahaya Pantura sebanyak 40 orang. Untuk mengetahui hubungan masa kerja, gerakan repetitive dan postur kerja dengan kejadian CTS menggunakan Fisher's Exact Test.

\section{Hasil}

\section{A. Analisis Univariat}

1. Masa Kerja

Tabel 1. Distribusi Frekuensi Responden Berdasarkan Masa Kerja No Masa Frekuensi Persentase Kerja

\begin{tabular}{llll}
\hline 1. & Tidak & 9 & $22,5 \%$ \\
Berisiko & & \\
2. & Berisiko & 31 & $77,5 \%$ \\
\hline Jumlah & 40 & $100 \%$ \\
\hline
\end{tabular}

Berdasarkan tabel diatas diketahui bahwa responden yang berisiko berjumlah 31 orang $(77,5 \%)$ sedangkan responden yang tidak berisiko berjumlah 9 orang $(22,5 \%)$.

2. Gerakan Repetitive

Tabel 2. Distribusi Frekuensi Responden Berdasarkan Gerakan Repetitive

\begin{tabular}{clcc}
\hline No & $\begin{array}{l}\text { Gerakan } \\
\text { Repetitif }\end{array}$ & Jumlah & $\begin{array}{c}\text { Persentase } \\
(\%)\end{array}$ \\
\hline 1. & Tidak & 22 & $55,0 \%$ \\
& Berisiko & & \\
2. & Berisiko & 18 & $45,0 \%$ \\
\hline & Total & 40 & $100 \%$ \\
\hline
\end{tabular}

Dari data diatas diketahui bahwa dari 40 responden yang masuk dalam kategori tidak berisiko berjumlah 22 orang $(55,0 \%)$ sedangkan responden yang masuk dalam kategori berisiko berjumlah 18 orang $(45,0 \%)$.

3. Postur Kerja

Tabel 3. Distribusi Frekuensi Responden Berdasarkan Postur Kerja

\begin{tabular}{cccc}
\hline No & $\begin{array}{c}\text { Level } \\
\text { Resiko }\end{array}$ & Jumlah & $\begin{array}{c}\text { Persentase } \\
(\%)\end{array}$ \\
\hline 1. & Kecil & 12 & $30,0 \%$ \\
2. & Tinggi & 28 & $70,0 \%$ \\
\hline & Total & 40 & 100 \\
\hline
\end{tabular}

Berdasarkan tabel 3 diatas diketahui bahwa dari 40 responden yang mempunyai level resiko kecil sebanyak 12 orang $(30,0 \%)$, dan yang mempunyai level resiko tinggi sebanyak 28 orang $(70,0 \%)$.

4. Kejadian CTS

Tabel 4. Distribusi Frekuensi Responden Berdasarkan Kejadian CTS

\begin{tabular}{clcc}
\hline No & $\begin{array}{c}\text { Keluhan } \\
\text { Subyektif }\end{array}$ & Jumlah & $\begin{array}{c}\text { Persentase } \\
(\%)\end{array}$ \\
\hline 1. & Ya & 30 & $75.0 \%$ \\
2. & Tidak & 10 & $25,0 \%$ \\
\hline & Total & 40 & $100 \%$ \\
\hline
\end{tabular}

Berdasarkan tabel 4 diatas diketahui bahwa dari 40 responden, diperoleh sebanyak 30 responden $(75,0 \%)$ mengalami kejadian CTS, sedangkan yang tidak mengalami keluhan subyektif kejadian CTS sebanyak 10 orang $(25,0 \%)$. 


\section{B. Analisis Bivariat}

Adapun hasil dari analisis bivariat pada penelitian ini, dimana melihat hubungan antar variabel dependen dan variabel independen. Hasil penelitian sebagai berikut:

Tabel 5. Analisis Hubungan Masa Kerja dengan Kejadian CTS

\begin{tabular}{|c|c|c|c|c|c|c|c|c|c|}
\hline \multirow[t]{2}{*}{ No } & \multirow{2}{*}{$\begin{array}{l}\text { Masa } \\
\text { Kerja }\end{array}$} & \multicolumn{2}{|c|}{ Kejadian CTS } & \multirow[t]{2}{*}{ Jumlah } & \multirow[t]{2}{*}{$\begin{array}{c}\mathrm{P} \\
\text { Value }\end{array}$} & \multirow[t]{2}{*}{$\mathrm{SC}$} & \multirow[t]{2}{*}{ RR } & \multicolumn{2}{|c|}{$\begin{array}{c}\text { 95\% Confidence } \\
\text { Interval }(\mathrm{CI})\end{array}$} \\
\hline & & $\mathrm{Ya}$ & Tidak & & & & & Lower & Upper \\
\hline \multirow[t]{2}{*}{1.} & Tidak & 4 & 5 & 9 & & & & & \\
\hline & Berisiko & $44,4 \%$ & $55,6 \%$ & $100,0 \%$ & & & & & \\
\hline \multirow[t]{2}{*}{2.} & Berisiko & 26 & 5 & 31 & 0,029 & $-0,380$ & 3,444 & 1,276 & 9,297 \\
\hline & & $83,9 \%$ & $16,1 \%$ & $100,0 \%$ & & & & & \\
\hline \multirow{2}{*}{\multicolumn{2}{|c|}{ Jumlah Total \% }} & 30 & 10 & 40 & & & & & \\
\hline & & $75,0 \%$ & $25,0 \%$ & $100,0 \%$ & & & & & \\
\hline
\end{tabular}

Berdasarkan uji statistik dengan hubungan antara masa kerja dengan Kejadian menggunakan nilai Fisher Exact Test, CTS pada karyawan SPBE di Indramayu diperoleh nilai probabilitas ( $P$ value $)$ sebesar Tahun 2017, Karena sebagian besar karyawan $0,029$ ( $\mathrm{P}$ value $<0,05)$ sehingga dapat SPBE memiliki masa kerja $>4$ tahun yang disimpulkan bahwa pada $\alpha(5 \%)$ terdapat dapat berisiko mengalami kejadian CTS.

Tabel 6. Analisis Hubungan Gerakan Repetitive dengan Kejadian CTS

\begin{tabular}{|c|c|c|c|c|c|c|c|c|c|}
\hline \multirow[t]{2}{*}{ No } & \multirow{2}{*}{$\begin{array}{l}\text { Gerakan } \\
\text { Repetitive }\end{array}$} & \multicolumn{2}{|c|}{ Kejadian CTS } & \multirow[t]{2}{*}{ Jumlah } & \multirow[t]{2}{*}{$\begin{array}{c}\mathrm{P} \\
\text { Value }\end{array}$} & \multirow[t]{2}{*}{$\mathrm{SC}$} & \multirow[t]{2}{*}{ RR } & \multicolumn{2}{|c|}{$\begin{array}{l}\text { 95\% Confidence } \\
\text { Interval (CI) }\end{array}$} \\
\hline & & $\mathrm{Ya}$ & Tidak & & & & & Lower & Upper \\
\hline \multirow[t]{2}{*}{1.} & Tidak & 15 & 7 & 22 & & & & & \\
\hline & Berisiko & $68,2 \%$ & $31,8 \%$ & $100,0 \%$ & & & & & \\
\hline 2. & Berisiko & $\begin{array}{c}15 \\
83,3 \%\end{array}$ & $\begin{array}{c}3 \\
16,7 \%\end{array}$ & $\begin{array}{c}18 \\
100,0 \%\end{array}$ & 0,464 & $-0,174$ & 1,909 & 0,575 & 6,342 \\
\hline \multirow{2}{*}{\multicolumn{2}{|c|}{ Jumlah Total \% }} & 30 & 10 & 40 & & & & & \\
\hline & & $75,0 \%$ & $25,0 \%$ & $100,0 \%$ & & & & & \\
\hline
\end{tabular}

Berdasarkan uji statistik dengan disimpulkan bahwa pada $\alpha(5 \%)$ tidak ada menggunakan nilai Fisher Exact Test, hubungan antara gerakan repetitive dengan diperoleh nilai probabilitas $(P$ value $)$ sebesar kejadian CTS pada karyawan SPBE di 0,464 ( $\mathrm{P}$ value $>0,05)$ sehingga dapat Indramayu Tahun 2017.

Tabel 7. Analisis Hubungan Postur Kerja dengan Kejadian CTS

\begin{tabular}{ccccccc}
\hline \multirow{2}{*}{ No } & \multirow{2}{*}{ Postur Kerja } & \multicolumn{2}{c}{ Kejadian CTS } & \multirow{2}{*}{ Jumlah } & \multirow{2}{*}{ P Value } & \multirow{2}{*}{ SC } \\
\hline \multirow{2}{*}{1.} & Kecil & 6 & Tidak & 6 & 12 & \\
\\
\multirow{2}{*}{2.} & $50,0 \%$ & $50,0 \%$ & $100 \%$ & & \\
& \multirow{2}{*}{ Tinggi } & 24 & 4 & 28 & & \\
& & $85,7 \%$ & $14,3 \%$ & $100 \%$ & 0,041 & $-0,378$ \\
& \multirow{2}{*}{ Jumlah } & 30 & 10 & 40 & & \\
\hline
\end{tabular}


Berdasarkan uji statistik dengan menggunakan nilai Fisher Exact Test, diperoleh nilai probabilitas ( $P$ value $)$ sebesar 0,041 ( $\mathrm{P}$ value $<0,05)$ sehingga dapat disimpulkan bahwa pada $\alpha(5 \%)$ terdapat hubungan antara postur kerja dengan kejadian CTS pada karyawan SPBE di Indramayu Tahun 2017

\section{Pembahasan}

\section{Masa Kerja}

Tabel 1 menunjukan hasil bahwa dari 40 karyawan SPBE yang memiliki masa kerja 4-7 tahun berjumlah 31 orang $(77,5 \%)$ dan yang memiliki masa kerja 1-3 tahun berjumlah 9 orang $(22,5 \%)$. Sebagian besar karyawan yang memiliki masa kerja 4-7 tahun masuk dalam kategori berisiko.

Faktor risiko terjadinya Carpal Tunnel Syndrome terdiri dari beberapa faktor dan salah satunya adalah masa kerja. Masa kerja merupakan salah satu faktor yang dapat mendukung munculnya gangguan musculoskeletal yang disebabkan oleh pekerjaan.Proporsi CTS lebih banyak ditemukan pada responden yang mempunyai masa kerja $\geq 4$ tahun, dibandingkan dengan responden dengan masa kerja $\leq 4$ tahun yang mengalami kejadian positif. Semakin lama masa kerja seseorang maka semakin banyak gerakan berulang yang telah dilakukan ${ }^{10}$.

\section{Gerakan Repetitive}

Berdasarkan tabel 2 menunjukan hasil bahwa dari 40 karyawan SPBE yang melakukan gerakan repetitive sebanyak 18 orang $(45,0 \%)$ dan yang tidak melakukan gerakan repetitive sebanyak 22 orang $(55,0 \%)$. Sebagian besar karyawan tidak melakukan gerakan repetitive masuk dalam kategori tidak beresiko.

Gerakan repetitive merupakan gerakan yang memiliki sedikit variasi dan dilakukan setiap beberapa detik, sehingga dapat mengakibatkan kelelahan dan ketegangan otot tendon. Jika waktu yang digunakan untuk istirahat tidak dapat mengurangi efek tersebut. Cedera gerakan berulang mengakibatkan kerugian besar dalam hal biaya perawatan untuk tenaga kerja, selain tenaga kerja yang menderita, akan kehilangan produktifitas optimalnya. Hal ini dapat menjadi beban bagi tenaga kerja maupun pada perusahaan. Dalam penelitian ini menunjukan bahwa Sebagian besar karyawan tidak melakukan gerakan repetitive sehingga bisa masuk dalam kategori tidak beresiko ${ }^{11}$.

\section{Postur Kerja}

Berdasarkan tabel 3 menunjukan hasil bahwa dari 40 karyawan SPBE yang mempunyai level risiko kecil sebanyak 12 $(30,0 \%)$ dan yang mempunyai level risiko tinggi sebanyak 70,0 (70,0\%). Sebagian besar karyawan mempunyai level risiko tinggi.

Posisi kerja statis dan postur tangan tidak ergonomis pada bahu, lengan, dan pergelangan tangan dalam jangka waktu yang lama akan menyebabkan peradangan pada jaringan otot, syaraf, maupun keduanya. Pembengkakan tersebut akan menekan saraf medianus tangan sehingga bisa menimbulkan $\mathrm{CTS}^{12}$.

\section{Kejadian CTS}

Berdasarkan tabel 4 menunjukan hasil bahwa dari 40 karyawan SPBE yang mengalami kejadian CTS sebanyak 30 orang $(75,0 \%)$ dan yang tidak mengalami kejadian CTS sebanyak 10 orang $(25,5 \%)$. Sebagian besar karyawan mengalami kejadian CTS.

Carpal Tunnel Syndrome (CTS) adalah gangguan pada anggota tubuh bagian tangan yang menyebabkan rasa sakit dan mati rasa terutama pada ibu jari dan tiga jari utama yaitu jari telunjuk, jari tengah, dan sebagian jari manis $^{13}$.

Penyebab utama CTS sering sangat sukar ditentukan, apakah karena kondisi kerja atau karena suatu penyakit. penyebab dasar dari keluhan tidak dapat ditemukan. Namun karena desakan ekonomi yang menuntut untuk tetap melakukan pekerjaan tersebut dan pada akhirnya gejala yang dirasakan dianggap 
keadaan biasa dengan hanya mengobati dengan pengobatan seadanya, hal ini dapat menjadikan keadaan yang biasa menjadi penyakit serius ${ }^{14}$.

\section{Hubungan Masa Kerja dengan Kejadian CTS}

Berdasarkan uji statistik diperoleh nilai ekspektasi $<5$ sehingga digunakan nilai Fisher Exact Test sebesar 0,029 sebagai ganti nilai $\mathrm{P}$ value, karena nilai $\mathrm{P}$-value $<0,05$ maka Ho ditolak, artinya terdapat hubungan antara masa kerja dengan Kejadian CTS pada karyawan SPBE di Indramayu Tahun 2017.

Hal ini sesuai dengan penelitian yang telah dilakukan Permatasari, V. F, (2016) yang menyatakan bahwa adanya hubungan yang bermakna antara masa kerja dengan sindrom terowongan karpal ${ }^{14}$.

Analisis hasil jawaban pertanyaan (kuesioner) mengenai masa kerja yaitu terdapat pada kategori masa kerja yang berisiko sebanyak 31 . Hal ini menggambarkan bahwa semakin lama masa kerja yang dilalui karyawan maka semakin berisiko mengalami CTS, begitu juga sebaliknya semakin rendah masa kerja yang dilalui karyawan maka semakin rendah risiko mengalami CTS.

\section{Hubungan Gerakan Repetitive dengan Kejadian CTS}

Berdasarkan uji statistik dengan menggunakan nilai Fisher Exact Test, diperoleh nilai probabilitas ( $\mathrm{P}$ value) sebesar $0,464(\mathrm{P}$ value $>0,05)$ sehingga dapat disimpulkan bahwa pada (5\%) tidak ada hubungan antara gerakan repetitive dengan kejadian CTS.

Hal ini bertolak belakang dengan penelitian yang dilakukan Rina, T.I.M. (2010), bahwa terdapat hubungan antara gerakan repetitive dengan kejadian terowongan karpal pada pekerjaan menjahit di bagian konveksi PT. Liris Sukoharjo di Desa Banaran Kecamatan grogol Kabupaten sukoharjo dengan nilai $p$ value $<0,05$.
Analisis hasil observasi mengenai gerakan repetitive yaitu terdapat pada kategori gerakan repetitive yang tidak berisiko sebanyak 22 . Hal ini menggambarkan bahwa semakin sedikit gerakan repetitive yang dilakukan karyawan maka semakin rendah risiko mengalami CTS, begitu juga sebaliknya semakin banyak gerakan repetitive yang dilakukan karyawan maka semakin tinggi risiko mengalami CTS.

\section{Hubungan Postur Kerja dengan Kejadian CTS}

Berdasarkan uji statistik dengan menggunakan nilai Fisher Exact Test, diperoleh nilai probabilitas $(P$ value) sebesar $0,041 \quad(\mathrm{P}$ value $<0,05)$ sehingga dapat disimpulkan bahwa pada $\alpha \quad(5 \%)$ terdapat hubungan antara postur kerja dengan kejadian CTS.

Posisi tubuh yang tidak alamiah dan cara kerja yang tidak ergonomis dalam waktu lama dapat menyebabkan berbagai gangguan kesehatan pada karyawan, salah satunya kesulitan menggerakan kaki, tangan, leher atau kepala. Bagi karyawan, adanya aktivitas di Filling Hall merupakan suatu kegiatan yang sangat berarti karena dapat dijadikan sebagai sumber mata pencaharian yang dapat meningkatkan penghasilan ekonomi, Padahal perlu disadari bahwa setiap pekerjaan memiliki tingkat risiko yang berbeda-beda.

Penelitian ini sesuai dengan penelitian yang dilakukan oleh Ahmad Iqbal Lazuardi (2016) yang menyatakan bahwa ada hubungan antara postur kerja dengan kejadian Carpal Tunnel Syndrome pada pekerja pemecah batu di kecamatan sumbersari dan sukowono kabupaten jember dengan nilai $\mathrm{P}$-value $<0,05^{10}$.

\section{Kesimpulan}

1. Distribusi masa kerja pada karyawan SPBE di Indramayu Tahun 2017, sebagian besar karyawan yang memiliki masa kerja 4-7 tahun 
berjumlah 31 orang $(77,5 \%)$ sehingga masuk dalam kategori berisiko.

2. Distribusi gerakan repetitive pada karyawan SPBE di Indramayu Tahun 2017, sebagian kecil karyawan yang melakukan gerakan repetitive $\geq 30$ kali berjumlah 18 orang $(45,0 \%)$ sehingga masuk dalam kategori tidak beresiko.

3. Distribusi postur kerja pada karyawan SPBE di Indramayu Tahun 2017, sebagian besar karyawan yang mengalami level risiko tinggi berjumlah 28 orang $(70,0 \%)$.

4. Terdapat hubungan yang cukup kuat antara masa kerja dengan kejadian CTS pada karyawan SPBE di Indramayu Tahun 2017.

5. Terdapat hubungan yang lemah antara gerakan repetitive dengan kejadian CTS pada karyawan SPBE di Indramayu Tahun 2017.

6. Terdapat hubungan yang tinggi antara postur kerja dengan kejadian CTS pada karyawan SPBE di Indramayu Tahun 2017.

\section{Saran}

1. Bagi Puskesmas

Bagi puskesmas khususnya yang memegang program kesehatan kerja diharapkan melakukan pembinaan terhadap karyawan SPBE di Indramayu, serta melakukan penyuluhan-penyuluhan secara rutin.

2. Bagi Fakulta

Informasi yang diperoleh dari hasil penelitian ini dapat dijadikan sebagai salah satu referensi untuk penelitian lebih lanjut bagi mahasiswa yang melakukan penelitian penyakit akibat kerja khususnya tentang kejadian CTS.

3. Bagi Pemilik SPBE

Bagi pemilik SPBE diharapkan ikut memberikan penyuluhan tentang postur kerja/ posisi yang baik / ergonomis sehingga dapat mengurangi kejadian CTS

4. Bagi Karyawan SPBE

Diharapkan dapat melakukan istirahat secara teratur setiap 15-20 menit dengan melekukkan dan meluruskan pergelangan tangan. Lakukan latihan dengan mengepal, menekuk ke arah bawah dan ke atas kemudian tahan selama 30 detik.

5. Bagi Peneliti Lain

Untuk peneliti selanjutnya diharapkan dapat meneliti variabel-variabel lain seperti getaran, riwayat penyakit dan lain sebagainya yang merupakan faktor risiko terjadinya CTS pada karyawan SPBE. Sehingga dapat memberikan hasil yang berbeda dan tertarik untuk diteliti oleh peneliti selanjutnya.

\section{Daftar Pustaka}

1. Dinas Tenaga Kerja dan Transmigrasi, 2013, Definisi tenaga kerja, Jawa Timur, Disnakertrans.

2. OSHA. 2008. Musculoskeletal Disorders [edisi Online] https://www.osha.gov/SLTC/ergonimic/ [Di akses 12 Mei 2017].

3. Yassi, Annalee. 1997. Repetitive Starin Injuries (Occupational Medicine), Occupational and Enviromental Health of Unit. University of Manitoba. Canada. Lancet.1997. Vol 349 99056) pp. 943-947.

4. Srie Ramadhani, 2003. Ergonomi dalam Bunga Rampai Hiperkes \& KK Edisi Kedua (Revisi), Budiono, A.M. Sugeng, Jusuf, R.M.S. \& Pusparini, Adriana, Badan Penerbit Universitas Diponegoro, Semarang.

5. Shigeharu,U. 2010. Current conceptsof carpal tunnel syndrome: pathophysiology, treatment, and evaluation. Journal of Ortophaedic Science, 15(1):1-13. 
6. Tana, L. 2004. Sindrom Terowongan Karpal pada Pekerja : Pencegahan dan Pengobatannya. Jurnal Kedokteran Trisakti Vol. 22 No 3.

7. Harahap, Rudiansyah. 2003. Praktis Carpal Tunnel Syndrome. Cermin Dunia Kedokteran No. 141. Semarang.

8. Notoatmodjo, S. 2012. Metode Penelitian Kesehatan. Jakarta : Rineka Cipta.

9. Notoatmodjo, S. 2010. Metode Penelitian Kesehatan. Jakarta : Rineka Cipta.

10. Ahmad, I L. 2016. Determinan Gejala Carpal Tunnel Syndrome (CTS) pada pekerja pemecah batu (Studi pada Pekerja Pemecah Batu di kecamatan Sumbersari dan Sukowono Kabupaten Jember). Skripsi. Fakultas Kesehatan Masyarakat, Universitas Jember.

11. Rusdi Yusuf, Koesyanto Herry. Hubungan Antara Getaran Mesin pada Pekerja Bagian Produksi dengan Carpal Tunnel Syndrome Industri Pengolahan Kayu Brumbung Perum Perhutani Unit I Jawa Tengah. Jurnal KEMAS 5 (2) (2010) 89-94.

12. Wichaksana, Aryawan, Kartiena A. 2002. Peran Ergonomi dalam Pencegahan Sindroma Carpal Tunnel Akibat Kerja. PPS. K, Hiperkes Medis. Fakultas Kedokteran Universitas Indonesia, Jakarta. Cermin Dunia Kedokteran No.136,.

13. Yassi, Annalee. 1997. Repetitive Starin Injuries (Occupational Medicine), Occupational and Enviromental Health of Unit. University of Manitoba. Canada. Lancet.1997. Vol 349 99056) pp. 943947.

14. Veni, F P. 2016. Hubungan Masa Kerja Dan Gerakan Repetitif Dengan Kejadian Sindrom Terowongan Karpal
Pada Pekerja Industri Keripik Melinjo Subur Indramayu. Skripsi. Fakultas Kesehatan Masyarakat, Universitas Wiralodra Indramayu. 